\title{
A mulher negra viajante: experiências e estratégias de combate à sua (in)visibilidade no turismo
}

\section{The black woman traveler: experiences and strategies to combat their (in)visibility in tourism}

Joice dos Santos

Bacharel em Turismo e Hotelaria pela Universidade do Estado da Bahia - UNEB, Salvador/BA, Brasil

E-mail: joicee1503@gmail.com

Natália Silva Coimbra de Sá

Professora Adjunta no Departamento de Ciências Humanas da Universidade do Estado da Bahia - UNEB, Salvador/BA, Brasil

E-mail: natalia.coimbra@gmail.com

Artigo recebido em: $16-12-2020$

Artigo aprovado em: 07-04-2021 


\section{RESUMO}

Este artigo tem como objetivo evidenciar a presença de mulheres negras viajantes no turismo como estratégia de combate ao racismo. Essa discussão é relevante no contexto da representatividade, pois questiona sobre a invisibilidade das mulheres viajantes e seu impacto no imaginário do que é ser turista e como esta categoria é vista socialmente, buscando desmistificar a imagem do turista branco como o único tipo de consumidor do turismo. Foi utilizada a metodologia de caráter qualitativo, descritivo e exploratório, pautada em pesquisa bibliográfica, documental e com levantamento de dados online, identificando os casos para análise por meio de redes sociais; sites oficiais de empresas de afroturismo e/ou turismo afrocentrado, assim como iniciativas voltadas para mulheres negras viajantes; e plataformas de turismo reconhecidas pelo trade turístico e turistas como referências para busca de serviços de hospitalidade. Por fim, a partir da discussão teórica e da reflexão sobre os casos observados, chegou-se à conclusão de que é necessário um turismo antirracista, que reconheça e valorize as pessoas negras, em especial as mulheres, por serem o grupo mais invisibilizado pelo racismo, destacando seu papel como gestoras da atividade turística, empreendedoras e também como turistas. E que isso seja um compromisso de todos os atores que compõem o trade turístico, em especial aqueles responsáveis pelo marketing e pelo planejamento da atividade, pautados em políticas públicas que promovam a igualdade, a inclusão e o respeito no turismo.

Palavras-chave: Mulher Negra. Viajante. Turismo. Invisibilidade.

\section{ABSTRACT}

This article aims to highlight the presence of black women in the role of tourists as a strategy to combat racism. This discussion is relevant in the context of representativeness because it questions the invisibility of female travelers and its impact on the imaginary of what it is like to be a tourist and how this category is socially seen, looking to demystify the image of the white tourist as the only type of tourism consumer. A qualitative, descriptive, and exploratory methodology was used, based on bibliographic, documentary research and online data collection, identifying the cases for analysis through social networks; official websites of Afro tourism and/or Afrocentric tourism companies, as well as initiatives aimed at black women travelers; and tourism platforms recognized by the tourist trade and tourists as references for seeking hospitality services. Finally, from the theoretical discussion and reflection on the observed cases, it was concluded that anti-racist tourism is needed, which recognizes and values black people, especially women, for being the group that is most made invisible by racism, highlighting their role as managers of the tourist activity, entrepreneurs and also as tourists. And may it be a commitment of all the actors that make up the tourist trade, especially those responsible for the marketing and the activity planning, based on public policies that promote equality, inclusion, and respect in tourism.

Keywords: Black Woman. Traveler. Tourism. Invisibility. 


\section{INTRODUÇÃO}

O turismo é um fenômeno que se consolidou ao longo do tempo contribuindo com a diversidade natural e cultural do mundo e, simultaneamente, satisfazendo motivações, realizando sonhos e desejos das pessoas. Atualmente, assim como acontece em toda a sociedade, são percebidas mudanças de hábitos, valores e comportamentos no âmbito desta prática que, para além de sua importância como atividade econômica, destaca-se também por seus aspectos sociais e culturais.

Por exemplo, as mulheres passaram a marcar um novo perfil de viajantes, principalmente, porque elas têm vivido mais, têm menos filhos e têm ganhado independência financeira. Até o século XVI, para ser mulher, viajar e continuar sendo respeitável era preciso ser, em geral, uma rainha ou uma peregrina (Antonioli, 2015).

Durante muito tempo incidiram sobre as mulheres e suas liberdades de deslocamento, além de fatores relacionados a condições e gostos de classe, constrangimentos intrinsecamente atrelados ao fato de serem mulheres. No entanto, isso vem mudando. Apesar de o comportamento da mulher ainda gerar olhares preconceituosos e reações negativas por parte da sociedade machista, as mulheres têm enfrentado as opressões sofridas e ocupado os espaços que lhes pertencem por direito.

A partir do exposto, questiona-se sobre quem são essas mulheres que passaram a ter liberdade e ocupam esses espaços de viajante, visto que as mulheres negras estão na base da pirâmide social, com os menores salários e as maiores taxas de ocupações precárias e desemprego de toda a população (Instituto Brasileiro de Geografia e Estatística - IBGE, 2019). Não seriam elas, portanto, essas mulheres reconhecidas e donas desses espaços.

O racismo é estrutural e estruturante, impactando social, cultural, política e economicamente a sociedade, portanto, também na atividade turística. Dessa forma, com o intuito de enfrentamento desta ideologia, este artigo busca destacar a presença das mulheres negras no papel de turistas e consumidoras desse serviço e, em alguns casos, simultaneamente, como empreendedoras do setor, contrapondo à imagem divulgada na comunicação do turismo, na qual majoritariamente são representadas como objeto de consumo a ser explorado, exótico e hipersexualizado.

Essa discussão é importante para sociedade, pois questiona a invisibilidade das mulheres viajantes e seu impacto no imaginário sobre o que é ser turista e como esta é vista socialmente, problematizando a imagem principal divulgada pelo turismo de pessoas brancas como único 
perfil consumidor do turismo. Vale ressaltar que há poucas pesquisas acadêmicas sobre o tema, portanto, visando trazer contribuições à produção de conhecimento nesse campo de estudos.

A partir dessa perspectiva, o tema proposto pelo artigo surge devido ao aumento do deslocamento de mulheres negras com interesse em viagens culturais, em contrapartida à sua invisibilidade na comunicação turística e nos debates sobre gestão e planejamento do turismo. Para delimitar o estudo, partiu-se do questionamento: de que modo as mulheres negras atualmente têm buscado estratégias para contestar um modelo de turismo que tradicionalmente as invisibiliza como turistas?

O objetivo é evidenciar a presença de mulheres negras viajantes no turismo como estratégia de combate ao racismo. O estudo é exploratório e descritivo, caracterizando-se como uma pesquisa qualitativa, bibliográfica e documental, a partir também do levantamento em redes sociais, sites e plataformas de turismo que evidenciam empresas e grupos que estão produzindo narrativas, ações e mecanismos para democratizar e visibilizar a presença de mulheres negras no papel de turista.

$\mathrm{O}$ artigo está estruturado em cinco seções. A primeira traz a presente introdução. A segunda aborda o referencial teórico ao discutir a mulher no turismo e a imagem da mulher negra no turismo no Brasil. Em seguida, na terceira seção, é apresentada a metodologia da pesquisa. Na quarta seção são analisados dados sobre a mulher negra viajante no turismo, trazendo exemplos de existência e modos de resistência, registrando os resultados e discussões do trabalho. E, por fim, são apresentadas as considerações finais e as referências.

\section{REFERENCIAL TEÓRICO}

\subsection{A mulher no turismo}

De acordo com Swain (2005 com o citado em Murguialday, 2015), foi somente em meados da década de 1990 que surgiram estudos destacando que as questões de gênero são um elemento essencial para as pesquisas em turismo. Mais recentemente, a Organização Mundial do Turismo (OMT) e a Organização das Nações Unidas (ONU), em sua subdivisão voltada para a defesa dos direitos humanos das mulheres (ONU Mulheres), por meio do "Relatório Mundial sobre as Mulheres no Turismo", cuja primeira edição foi lançada em 2010 e a segunda em 2019, se uniram à tendência de visibilizar o papel das mulheres no setor (United Nations World Tourism Organization ${ }^{1}$ - UNWTO, 2019).

${ }^{1}$ Organização Mundial de Turismo 
Esses estudos relatam que, aos poucos, na produção intelectual sobre o tema, foram identificadas duas questões essenciais. Em primeiro lugar que observar a realidade pela perspectiva de gênero é fundamental, mas não apenas incluindo-as na atividade, pois há uma complexidade estrutural que as coloca em posição de desvantagem em relação aos homens. E, segundo, que a atividade turística tem efeitos positivos, mas também negativos, nas condições de vida das mulheres e, sobretudo, na sua posição em relação à discriminação e subordinação em relação à sociedade machista.

Essas questões são observadas tanto no que se refere ao papel da mulher como turista, quanto em relação ao seu papel como profissional do setor. Assim, identificou-se como essencial pensar a inserção, de um modo geral, da mulher no contexto da atividade turística.

Santos e Sá (2020) realizaram revisão de literatura sobre as interfaces entre racismo, intolerância religiosa e sexismo na indústria do turismo e as possibilidades de enfrentamento desse cenário na perspectiva do turismo étnico afro em Salvador-BA. A referida pesquisa de iniciação científica registrou duas tendências principais. A primeira sobre as dificuldades da mulher viajante solo, pautada por questões semelhantes à insegurança que as mulheres vivenciam em qualquer situação do dia a dia, desde perigos como a agressão verbal, a objetificação do corpo feminino, os assédios dos mais variados tipos, a exploração sexual, a violência física e até o feminicídio. E o segundo ponto, sobre a discriminação, estereótipos, subordinação e desvalorização do trabalho e das posições ocupadas pelas mulheres no mercado de trabalho voltado para o turismo e suas áreas afins.

Nesse sentido, foi identificado um número crescente de estudos, em sua maioria de autoras mulheres, que analisam os impactos da problemática de gênero no turismo abordando essas perspectivas por uma variedade de questões chave e enfoques: a participação das mulheres no mercado de trabalho, a divisão sexual do trabalho no turismo, quem controla os recursos, as oportunidades para o empreendedorismo feminino, a desvalorização social e econômica do trabalho feminino, o fortalecimento das organizações de mulheres e as novas lideranças femininas promovidas no âmbito do turismo, entre outros (Murguialday, 2015).

Por fim, uma outra tendência identificada a partir das fontes bibliográficas foi uma maior produção de pesquisas e publicações no idioma inglês e espanhol em relação aos estudos sobre a perspectiva de gênero e o papel da mulher. Em sua maioria, os estudos publicados na língua portuguesa, em especial os brasileiros, focam majoritariamente na temática do turismo sexual e na imagem de sexualização da mulher brasileira. Constatou-se uma lacuna no que se refere aos estudos que foquem principalmente nas representações das mulheres, de modo geral, assim 
como das mulheres negras, em especial, como turistas. Esta perspectiva conta com pouca representatividade nos estudos brasileiros, portanto, pretende-se com o presente artigo, contribuir para a ampliação do debate.

\subsection{A imagem da mulher negra no turismo no Brasil}

O racismo, pilar da construção social do Brasil, perpassa por todos os campos, e no turismo não seria diferente. Esse racismo, sendo estrutural, é o elemento que integra a organização econômica e política da sociedade. O racismo fornece o sentido, a lógica e a tecnologia para a reprodução das formas de desigualdade e violência que moldam a vida social contemporânea. (Almeida, 2019).

Entre as vertentes do preconceito, pode-se colocar o racismo como elemento principal da desigualdade nas relações sociais, sendo ela uma manifestação comum nas diversas sociedades (Almeida, 2019). E, ainda, destacar a mulher negra como vítima principal, pois, além de sofrer com o racismo, sofre também com o machismo.

As mulheres negras, que correspondem 28,7\% da população brasileira (IBGE, 2019), são as mais atingidas no âmbito da violência em relacionamentos afetivos, preteridas em entrevistas profissionais, ou ocupando subempregos. Destas, 65\% desempenham trabalhos domésticos, sendo que apenas $34 \%$ possui carteira assinada e média salarial menor que o salário mínimo. No sistema de saúde, as mulheres negras são as que mais sofrem com violência obstétrica, sendo a proporção de mortes maternas de mulheres negras 40,6\%, em comparação à de mulheres brancas, com 34,5\% (Instituto de Pesquisa Econômica Aplicada - IPEA, 2017). E, no que se refere aos meios de comunicação, estas são invisibilizadas enquanto pessoas detentoras de conhecimento e beleza, impactando na autoestima de expressiva parcela da população, ou seja, são atravessadas pelo racismo desde a infância até a fase adulta (Geledés, 2019).

Dentro deste contexto, ser mulher e negra faz com que a luta diária seja ainda maior. Além de questões que afetam toda a população negra, como a maior probabilidade de sofrer violência policial (Alma Preta, 2019; Sinhoretto \& Morais, 2018; Waiselfisz, 2012) e a estigmatização da própria cultura (Silva, 2016; Pinheiro, 2015; Calasans, Santos, Cruz, Santos \& Araújo, 2015), ainda sofrem com os reflexos da sexualização do corpo negro feminino (Gomes, 2009, 2010; Teles \& Adi, 2016). Essas questões afetam em proporção muito maior as mulheres negras em comparação com as mulheres brancas, um problema que surgiu da herança escravagista e que permanece nos dias atuais (Silva, 2016). 
Conforme afirma Carneiro (2011, p. 1), os fragmentos das relações estabelecidas historicamente repercutem até a contemporaneidade na vida dessas mulheres:

O que poderia ser considerado como história ou reminiscências do período colonial permanece, entretanto, vivo no imaginário social e adquire novos contornos e funções em uma ordem social supostamente democrática, que mantém intactas as relações de gênero segundo a cor ou a raça instituídas no período da escravidão. As mulheres negras tiveram uma experiência histórica diferenciada que o discurso clássico sobre a opressão da mulher não tem reconhecido, assim como não tem dado conta da diferença qualitativa que o efeito da opressão sofrida teve e ainda tem na identidade feminina das mulheres negras.

Percebe-se essa prática violenta na comunicação do turismo quando apresenta a mulher negra como "mulata de carnaval", estereotipando-a, resultando em uma imagem totalmente erotizada, estimulando a exploração sexual ${ }^{2}$. Sabe-se que muitas viagens, em especial para o Brasil, são motivadas a partir desse imaginário (Gabrielli, 2006, 2011). Há ainda uma narrativa simbólica da mídia, quando usa a expressão "povo caloroso" relacionado com regiões ou destinos de sol e praia, seguida com a imagem da mulher negra, para dar-se subjetivamente a ideia de pessoa calorosa, ou seja, a figura da mulher negra calorosa. Nesse sentido, de acordo com Hintze (2013), a mídia contribui como agente de fortalecimento dessas questões, agindo como instrumento de dominação e/ou simbologia imagética da invisibilidade.

Além disso, a pouca representação negra enquanto turista nos principais meios midiáticos causa uma submissão na perspectiva do pensamento racial. O padrão eurocêntrico alimenta o perfil imaginário do que é ser turista, tornando a imagem de pessoas negras como turistas censurada ou até inexistente. E, quando se é mulher negra, esta imagem aparece apenas como produto de consumo sexual a ser explorado (Santos, Berteli \& Arantes, 2016).

[...] Mais que qualquer grupo de mulheres nesta sociedade, as negras têm sido consideradas "só corpo, sem mente". A utilização de corpos femininos negros na escravidão como incubadoras para a geração de outros escravos era a exemplificação prática da ideia de que as "mulheres desregradas" deviam ser controladas. Para justificar a exploração masculina branca e o estupro das negras durante a escravidão, a cultura branca teve que produzir uma iconografia de corpos de negras que insistia em representá-las como altamente dotadas de sexo, a perfeita encarnação de um erotismo primitivo e desenfreado (Hooks, 1995, p. 469).

Corroborando com Hooks (1995), Hintze (2013) afirma que o negro é aquele que serve nos bastidores do turismo. Sua imagem de servidor do turismo é recorrente: lazer e trabalho paradoxalmente unidos. Portanto, se pessoas negras são destacadas e representadas somente

2 O turismo sexual não deve ser interpretado como segmento, mas, sim, como efeitos negativos do desenvolvimento desordenado e inconsequente da atividade turística. 
como instrumento para proporcionar lazer para as pessoas brancas, pressupõe-se que as primeiras não podem existir enquanto consumidoras do turismo.

Nesse sentido, o corpo da mulher negra é comumente reconhecido como atrativo turístico brasileiro e este olhar impacta da mesma forma quando elas estão no papel de turista. É recorrente o discurso de que uma mulher negra viajando para o exterior, à primeira instância, é para se prostituir e, no caso das brasileiras, o fetiche é ainda mais explícito. Há diversos relatos de mulheres viajantes que afirmam ter sofrido algum tipo de assédio, apenas por afirmarem serem brasileiras e, quando se é negra, a relação "samba e prostituição" está intrinsecamente nas percepções daqueles que as recebem nos destinos visitados (Piscitelli, 2007a, 2007b; Gomes, 2011; Gabrielli, 2006, 2011; Santos, Berteli \& Arantes, 2016)

Santos (2018), em sua pesquisa qualitativa, constatou que $46,7 \%$ de negros e negras relatam que já vivenciaram situações de racismo e/ou injúria racial em viagens pelo Brasil. E também, que há menor porcentagem de pessoas negras viajando em relação a viajantes brancos devido ao medo de sofrer violência racial, mesmo os negros sendo maioria da população brasileira, correspondendo a 56,10\% da população nacional (IBGE, 2019). Esses dados, de certo, apontam para uma grande contradição.

Quando se é negro as possibilidades de mundo são apresentadas de maneira diferente e, por muitas vezes, fazem com que as pessoas negras acreditem que estas nem ao menos existem. A baixa representatividade negra na mídia e/ou nos ambientes sociais de destaque impede que a população negra enxergue-se como exemplos, como também não veem suas experiências de vida como parte dos padrões. Portanto, se uma pessoa negra vive em um ambiente em que nenhuma negra viaja; se a mídia não apresenta nenhuma negra pelo mundo; se as pessoas nunca sentem que esta seria uma possibilidade para si, por que considerariam viajar?

É o que a socióloga Collins (2019) chama de “imagem do controle", relações de poder social que são aplicadas às mulheres negras, que permitem que outras pessoas as tratem de determinada maneira. E, se as mulheres negras acreditam nessas imagens, elas internalizam esse comportamento e se portam de determinada forma.

As pessoas estão envoltas por simbologias que influenciam diretamente seus desejos e ações. Se há somente referências negativas, ou nenhuma referência, consequentemente não se verão como protagonistas destas ações. Além disso, há ainda a ideia de que a comunidade negra é desprovida de recursos para viajar e a noção racista de que viajar não é uma atividade que lhe pertence, cabendo às pessoas negras somente o papel de servidão. Por isso, a 
representatividade ${ }^{3}$, termo utilizado frequentemente nas mídias e redes sociais, é necessária e de extrema importância. É preciso urgentemente mudar esse padrão de como as pessoas negras são representadas e, principalmente, a mulher negra.

No entanto, é importante ressaltar que não basta apenas ocupar esses espaços, é necessário questionar e gerar transformações reais no modo que o turismo percebe os negros e, em especial, as mulheres negras. É importante pensar em criar mecanismos que promovam a valorização das pessoas negras, do serviço oferecido por elas, valorizando sua cultura e personalidades que remetem ao povo negro. Ocupar apenas o espaço, sem buscar referências da sua história, de nada adianta. É preciso causar impactos nas pessoas que viajam e no destino visitado, gerando transformações em todo o sistema e nas práticas que envolvem o turismo, não apenas como atividade econômica, mas como fenômeno social e cultural.

\section{METODOLOGIA}

A pesquisa tem caráter qualitativo, quando as pesquisadoras se constituem no instrumento principal. Conforme Bogdan e Biklen (1994) consiste também em uma pesquisa descritiva, em que, interessando-se mais pelo processo do que pelos resultados, examinam os dados de maneira indutiva e privilegiam o significado. E é exploratória, pois, de acordo com Boaventura (2004) visa proporcionar maior familiaridade com o problema, com vistas a tornálo mais explícito ou construir hipóteses, pois, de modo geral, estas utilizam o levantamento bibliográfico e a análise de exemplos que estimulem a compreensão.

O tema e objeto de estudo contam com poucas publicações disponíveis, em especial com o enfoque aqui pretendido, podendo ser considerado um assunto ainda novo e pouco explorado. Diante disso, o ponto de partida foi identificar documentos oficiais, assim como pesquisas acadêmicas nacionais e internacionais, a partir das palavras-chave definidas. Com esses documentos - relatórios, artigos, dissertações, teses e livros, assim como dados de órgãos oficiais, pesquisas realizadas por sites reconhecidos e de referência e reportagens publicadas na mídia - foi possível elaborar a fundamentação teórica. E buscando também o diálogo com algumas autoras do pensamento feminista negro.

Em seguida, foi feito t5

\footnotetext{
${ }^{3}$ Apesar do conceito ter origem na política e na democracia, o termo é reivindicado pela sociedade civil enquanto movimentos identitários. Ou seja, não é apenas a organização de grupos buscando que seus interesses sejam representados e garantidos, mas é, sobretudo, parte da formação do que é o indivíduo que compõe esse grupo (Andrade, 2020).
} 
um levantamento nas redes sociais, de perfis de mulheres negras que produzem conteúdo sobre turismo para identificar, em especial, as que atuam de fato no mercado turístico, seja como empresárias e/ou promovendo estratégias e ações concretas, e não apenas escrevendo sobre suas próprias viagens, ainda que este tipo de conteúdo também seja considerado relevante para o problema posto inicialmente.

Chegou-se, assim, às quatro principais iniciativas aqui apresentadas: Diáspora.Black, Destino Afro, Brafrika e Bitonga Travel, além de outras que foram identificadas, como Black Bird e Go Diáspora. Em seguida, buscou-se conhecer suas histórias, a trajetória dos projetos e o impacto que esses exemplos podem trazer no que se refere às estratégias de atuação das mesmas e de que modo contribuem para as necessárias mudanças no mercado, em relação à imagem da mulher negra como turista e a sua importância no que se refere à representatividade para outras mulheres negras viajantes.

\title{
4. A MULHER NEGRA VIAJANTE NO TURISMO: EXISTÊNCIA E RESISTÊNCIA
}

Com o objetivo de demonstrar à sociedade que pessoas negras também viajam, valorizando-as como turistas, muitas agências de viagem focadas no turismo afro ou afroturismo vêm crescendo e ganhando destaque. O turismo afro pode-se entender como parte do segmento do turismo étnico que, segundo a Organização Mundial de Turismo - OMT (2008, p. 17-18), corresponde às atividades turísticas:

\begin{abstract}
decorrentes da vivência de experiências autênticas em contatos diretos com os modos de vida e a identidade de grupos étnicos. Busca-se estabelecer um contato próximo com a comunidade anfitriã, participar de suas atividades tradicionais, observar e aprender sobre suas expressões culturais, estilos de vida e costumes singulares.
\end{abstract}

Enquanto isso, o turismo afro, especificamente, tem como objetivo um turismo de experiência das manifestações culturais materiais e imateriais da população negra. Pinho (2018) ainda explica que o turismo étnico tem como prioritária a busca da diferença, enquanto que no turismo afrocentrado os turistas viajam em busca dos seus semelhantes.

Ou seja, o turismo étnico busca a diferença do outro. No que se refere ao turismo afrocentrado, ele surge com a intenção não apenas de valorizar a cultura afro, mas de resgate da história e da ancestralidade em contextos sociais e individuais, além de centralizar o negro como agente da atividade (Santos, 2018).

É a partir desse olhar que surgem as agências de viagens afrocentradas, buscando estimular mais pessoas negras a viajarem e, principalmente, as mulheres negras solo. Além de trabalharem roteiros para destinos já consagrados, essas agências criam também roteiros 
personalizados, focados no turismo de vivência e conexão, trazendo pessoas negras como protagonistas.

Essas iniciativas são inspiradas no Black Travel Movement, surgido nos Estados Unidos e desenvolvido por negros e latinos, a partir de 2015, com o objetivo de evidenciar que os negros embarcam em viagens de lazer, não apenas para trabalhar, e têm participação relevante no setor do turismo. No Brasil, surgiram algumas empresas como Diáspora.Black, plataforma online fundada em novembro de 2016, que conecta pessoas negras. Nesta plataforma pode-se encontrar serviço de reserva de hospedagem, semelhante ao oferecido pelo AirBnb, site de reservas de hospedagem em que pessoas comuns alugam suas casas ou quartos. No entanto, o grande diferencial é que qualquer pessoa pode alugar e em qualquer lugar, de bairros periféricos a bairros nobres, sem distinção e preconceito.

Vale ressaltar que a ideia de fundar uma startup de afroempreendedorismo surgiu para disponibilizar uma plataforma digital em que as pessoas negras pudessem se conectar, promovendo a hospitalidade em locais de cultura afrodescendente como comunidades quilombolas, terreiros de religiões de matriz africanas e coletivos de mulheres negras. Isso aconteceu após um dos sócios desta empresa sofrer racismo ao oferecer sua casa como hospedagem (Domingos, Pimentel \& Nogueira, 2018). Além desse serviço, a plataforma online oferece cursos sobre cultura negra e atua na área de negócios e gestão de forma acessível, criando um intercâmbio de pessoas virtualmente, além de realizar roteiros turísticos afrocentrados para diversos destinos turísticos.

A Destino Afro e a Brafrika são duas agências online, uma de Salvador e a outra de São Paulo, respectivamente, que criam pacotes em grupos e individuais de viagens, estimulando pessoas negras a conhecerem destinos que tragam uma conexão com sua ancestralidade, através do conhecimento da sua história ancestral e raízes, resgatando personalidades negras. Seus principais destinos são países do continente africano. No entanto, há também roteiros para países como a Colômbia, na América do Sul, focados em conhecer a cultura negra daquele país, algo que pouco se divulga nos meios de comunicação turística. Outro destino que trabalham é Paris que, apesar de ser um destino já consagrado e desejado pelos turistas, o roteiro tem como diferencial passeio pelo bairro Château D'Eau, um bairro negro dentro da cidade, contando histórias e fatos que remetem ao povo negro parisiense.

Essas agências não trabalham apenas com viagens internacionais, há roteiros para regiões quilombolas como, por exemplo, o Quilombo dos Palmares, no estado de Alagoas, a cidade de Cachoeira, localizada no Recôncavo Baiano, entre outros. Sempre focando no aspecto 
de pessoas negras como protagonistas do turismo, desmistificando fatos comumente apresentados e percebidos com um olhar eurocêntrico. Importante ressaltar também que as agências não atendem como clientes apenas pessoas negras, estando abertas a todos os públicos, porém, nos roteiros e na história, negros e negras são os destaques.

Para a proprietária da Brafrika, Beatriz Souza “democratizar o turismo aos negros é lutar contra o racismo" (Alma Preta, 2019). A agência, através da sua publicidade, busca resgatar a ideia das origens hereditárias, da ancestralidade e do negro como protagonista, promovendo viagens para destinos que falem da sua história ancestral e criando laços de identificação com lugar (Brafrika, 2020).

Além desses exemplos, podem ser citados outros, centrados no afroturismo e que têm surgido em anos recentes, como a Black Bird, empresa que busca contribuir com um olhar inclusivo para o mercado de turismo brasileiro. Nas suas plataformas são compartilhados relatos de viajantes negros, histórias de lugares e da cultura negra, além de inspirar novas narrativas e viagens, com dicas e promoções de roteiros especiais de turismo afro-referenciado, buscando ampliar a representatividade.

Há ainda a Go Diáspora, pioneira na inclusão de países da África e sua diáspora no seu portfólio de viagens voltadas para educação e vivência internacional, sendo a primeira agência de intercâmbio do Brasil a focar principalmente em países onde a cultura negra se faz mais fortemente presente. Destacando que, assim como as demais, a agência não atua apenas nestes destinos, trabalhando também com todos os tipos de países que oferecem opções de intercâmbio.

Assim, percebe-se que, a cada dia, surgem novos participantes no trade turístico dedicados a ocupar esse necessário espaço e lugar de fala no que se refere à valorização e divulgação das experiências das pessoas negras no turismo enquanto consumidoras. Ainda que seja necessário que lutem contra a imposição de uma perspectiva hegemônica eurocêntrica e elitista no que se refere à divulgação da imagem dos negros e negras nos meios de comunicação massivos e no planejamento público e oficial do turismo. Esse espaço vem sendo conquistado a partir das pressões exercidas por movimentos da sociedade civil.

No Brasil, o turismo movimentou cerca de R \$238,6 bilhões em 2019, um crescimento de 2,2\% em comparação a 2018 (Brasil, 2020). Apesar desses valores e do potencial turístico de um país de maior população negra fora do continente africano, não é possível traçar um percentual por raça desses viajantes, pois as agências reguladoras não exigem registro de raça 
nos cadastros. Será que não há lucro proveniente desse público ou seria falta de interesse por parte dos gestores em investir nesse mercado?

Uma pesquisa realizada pelo site TripAdvisor (2015) revelou dados sobre viagens feitas por mulheres do mundo inteiro. Responderam ao questionário 9.852 mulheres, sendo 671 brasileiras. O levantamento identificou que uma em cada quatro mulheres brasileiras viajou sozinha no período e que planejava repetir a viagem de duas a quatro vezes nos 12 meses seguintes. Os principais motivos pelos quais viajavam sozinhas eram: a liberdade de escolher o que querem fazer (65\%) e a falta de tempo e/ou recursos financeiros de amigos e familiares (30\%). O estudo ainda revelou que viajar sozinha dá mais independência (50\%), mais confiança $(52 \%)$ e experiência com a cultura $(51 \%)$.

No entanto, quem são essas mulheres? Se não há na pesquisa um recorte dos dados por raça, não é possível saber quantas mulheres negras fazem parte desse universo, ficando nítido o seu apagamento e/ou a falta de interesse em compreender e promover, de fato, a diversidade no mercado turístico.

Nessa perspectiva destaca-se a Bitonga Travel, um coletivo que propõe a visibilidade de mulheres negras, latinas e africanas em trânsito e movimento pelo mundo, idealizado por Rebecca Alethéia. O projeto estimula que as mulheres negras compartilhem suas histórias de viagem com intuito de potencializar para meninas e mulheres esse sonho que parece distante. Com o uso da hashtag \#BitongaTravel é possível aparecer na página do instagram e, assim, inspirar outras mulheres negras a viajarem solo ou acompanhadas. A Bitonga Travel, além de sua página no instagram, também possui um podcast. Neste, semanalmente, uma mulher negra é entrevistada para contar sobre algum destino para o qual viajou. O coletivo foca em mulheres negras do mundo todo, sem distinção de origem ou classe econômica.

Essas iniciativas promovem a expressividade de mulheres a viajarem e acreditarem que elas podem ser donas da sua história. No entanto, percebe-se que esse movimento fica restrito a um grupo, aquele que consome esse tipo de conteúdo nas redes sociais, não sendo divulgado em outros meios de comunicação de massa e nem do turismo. E também não é visto como um potencial nicho de mercado a ser explorado. Não há pacotes, nem divulgação em agências tradicionais para esse público, ou ações de marketing mais amplas direcionadas para as mulheres turistas, e muito menos às mulheres negras.

Além disso, enquanto não são criadas políticas públicas para esse perfil de viajantes, há pessoas negras se organizando e criando formas de resistir, tanto como profissional quanto no papel de turista. Hooks (1995) afirma que, numa cultura racista e sexista, as mulheres negras 
devem criar estratégias para contrapor a baixa autoestima imposta a elas. Estratégias que valorizem seu próprio trabalho, mesmo que este não seja legitimado por estruturas hegemônicas. E é nessa perspectiva que o movimento de mulheres negras no turismo acontece, criando espaços de resistência, educação e criatividade, onde podem exercer o poder de se auto representar e de intervenção política.

\section{CONSIDERAÇÕES FINAIS}

A ausência de discussões a respeito da presença da mulher negra no papel de viajante, e sua invisibilidade enquanto protagonista e com espaço de fala reconhecido no turismo, levou à produção deste artigo. Sendo perceptível que esse apagamento é devido ao racismo e ao machismo que envolve as relações sociais, com repercussões políticas, culturais e econômicas, nas quais a atividade turística também se encontra inserida.

$\mathrm{O}$ artigo buscou trazer a visibilidade das mulheres negras, porém, ainda que tenha sido possível identificar algumas iniciativas relevantes, fica ainda evidente a baixa ou quase nenhuma representatividade destas no chamado turismo convencional. Isso também foi observado nas produções científicas, devido à dificuldade de encontrar publicações a respeito do assunto.

Diante desse contexto, entende-se que se trata de um estudo exploratório, mas que abre diversas perspectivas para pesquisas futuras, como, por exemplo: um aprofundamento nas ações das iniciativas identificadas; um mapeamento mais amplo de outras experiências de afroempreendedoras no turismo; um estudo sobre o perfil de turistas negras, suas características, motivações e vivências; entre outros inúmeros caminhos possíveis.

No entanto, a partir dos resultados aqui apresentados, defende-se que o surgimento e a atuação das empresas citadas no estudo e a sua divulgação por meio de mulheres negras viajantes, bem como a atuação do coletivo Bitonga Travel nas redes sociais, pode impulsionar e abrir portas para ampliar o debate e, consequentemente, contribuir para o maior deslocamento e valorização da comunidade negra no papel de viajante.

Para concluir, é necessário repensar a atividade turística de modo que esta promova a equidade de gênero na sua agenda política, inclua a mulher negra nesse contexto, e crie políticas públicas inclusivas. Assim como o combate à publicidade que desumaniza e erotiza mulheres e crianças negras e a busca por soluções reais de combate ao racismo, dando escuta às vozes que ecoam por todo espaço. 


\section{REFERÊNCIAS}

Almeida, S. L. (2019). Racismo Estrutural. São Paulo: Sueli Carneiro, Pólen.

Alma Preta, Jornalismo Preto e Livre (2019). Anuário da Violência: 75\% dos mortos pelas polícias brasileiras são negros. Recuperado em 23, agosto, 2020, de

https://www.almapreta.com/editorias/realidade/anuario-da-violencia-75-dos-mortos-pelaspolicias-brasileiras-sao-negros

Alma Preta, Jornalismo Preto e Livre (2019). 'Democratizar o turismo aos negros é lutar contra o racismo', diz empresária. Recuperado em 24, agosto, 2020, de

https://almapreta.com/editorias/realidade/democratizar-o-turismo-aos-negros-e-lutar-contra-oracismo-diz-empresaria

Andrade, R. S. (2020). Representatividade: o que isso significa? Recuperado em 24, agosto, 2020, de https://www.politize.com.br/representatividade/

Antonioli, F. L. A. (2015). Viagens no feminino: gênero, turismo e transnacionalidade. Mestrado em Antropologia Social. Universidade Estadual de Campinas, Instituto de Filosofia e Ciências Humanas. Campinas, SP, Brasil. Recuperado em 16 agosto, 2020, de http://taurus.unicamp.br/bitstream/REPOSIP/279566/1/Antonioli_FernandaLeaoA._M.pdf

Bitonga Travel (2020). Democratizar viagens entre mulheres negras, latino americanas, caribenhas e africanas trazendo a visibilidade e retratos de suas histórias de viagem. Recuperado em 29, agosto, 2020, de https://bitongatravel.com.br/

Black Bird (2020). Viagem e representatividade. Recuperado em 29, agosto, 2020, de http://blackbirdviagem.com.br/

Boaventura, E. M. (2004). Metodologia da pesquisa: monografia, dissertação, tese. São Paulo: Atlas.

Bogdan, R. C., \& Biklen, S. K. (1994). Investigação qualitativa em educação: uma introdução à teoria e aos métodos. Portugal: Porto Editora.

Brafrika (2020). Sua viagem afrocentrada. Recuperado em 29, agosto, 2020, de https://brafrika.com.br/

Brasil. Ministério do Turismo (2020). Turismo movimentou $R \$ 238,6$ bilhões no Brasil em 2019, aumento de 2,2\%. Recuperado em 24, agosto, 2020, de http://www.turismo.gov.br/\%C3\%BAltimas-not\%C3\%ADcias/13379-turismomovimentou-r\$-238,6-bilh\%C3\%B5es-no-brasil-em-2019,-aumento-de-2,2.html

Calasans, B. S., Santos, E. A., Cruz, F. V., Santos, M. G. F., \& Araújo, M. C. (2015). Democracia racial e a estigmatização do negro na mídia e na sociedade brasileira. Anais do XVII Congresso de Ciências da Comunicação na Região Nordeste. Intercom - Sociedade Brasileira de Estudos Interdisciplinares da Comunicação. Natal, RN, Brasil. Recuperado em 23, agosto, 2020, de https://www.portalintercom.org.br/anais/nordeste2015/resumos/R470933-1.pdf 
Carneiro, S. (2011). Enegrecer o feminismo: a situação da mulher negra na América Latina a partir de uma perspectiva de gênero. Recuperado em 23, agosto, 2020, de https://www.geledes.org.br/enegrecer-o-feminismo-situacao-da-mulher-negra-na-americalatina-partir-de-uma-perspectiva-de-genero/

Collins, P. H. (2019). Pensamento feminista negro: conhecimento, consciência e a política do empoderamento. São Paulo: Boitempo Editorial.

Destino Afro (2020). Viagens afrocentradas. Recuperado em 29, agosto, 2020, de https://www.blacktravelers.com/destino-afro

Diáspora.Black (2020). Conecte-se à cultura negra em todo o mundo. Recuperado em 29, agosto, 2020, de https://diaspora.black/

Domingos, A. B., Pimentel, J. M. V., \& Nogueira, W. (2018). Diáspora.Black transformando a segregação em segmentação no turismo. Anais do $12^{\circ}$ Fórum Internacional de Turismo do Iguassu. Foz do Iguaçu, PR, Brasil. Recuperado em 29, agosto, 2020, de https://festivaldascataratas.com/forum-turismo/anais/2018/marketing-servicos/diaspora-blacktransformando-a-segregacao-em-segmentacao-no-turismo.pdf

Gabrielli, C. P. (2006). Das "vergonhas" descritas por Caminha, ao Turismo Sexual: o uso de imagens femininas atreladas ao desenvolvimento turístico do Brasil. Mestrado em Cultura e Turismo. Universidade Estadual de Santa Cruz, Ilhéus, BA, Brasil. Recuperado em 16, agosto, 2020, de

http://www.uesc.br/cursos/pos_graduacao/mestrado/turismo/dissertacao/dissertacao_cassiana _panissa.pdf

Gabrielli, C. P. (2011). Intersecções entre o mercado turístico e o mercado do sexo em Salvador, Bahia, Brasil. RBTUR - Revista Brasileira de Pesquisa em Turismo, 5(2), 136-156.

Geledés (2019). “Representatividade como construção da identidade”. Recuperado em 08, dezembro, 2020 de https://www.geledes.org.br/representatividade-como-construcao-da-identidade/

Go Diáspora (2020). Uma experiência de intercâmbio como você nunca viu! Recuperado em 29, agosto, 2020, de http://www.godiaspora.com.br/

Gomes, M. S. (2009). Marketing Turístico e Violência contra as Mulheres:

(des)(re)construções do Brasil como Paraíso de Mulatas. Mestrado em Sociologia. Programa de Pós-Graduação em Sociologia, Universidade Federal do Rio Grande do Sul. Porto Alegre, RS, Brasil. Recuperado em 23, agosto, 2020, de https://lume.ufrgs.br/handle/10183/18449

Gomes, M. S. (2010). A (des)(re)construção do Brasil como um Paraíso de Mulatas. Revista Eletrônica de Turismo Cultural, 4 (2). Recuperado em 23, agosto, 2020, de http://www.eca.usp.br/turismocultural/8.03_Mariana_Selister.pdf

Gomes, M. S. (2011). Mulheres brasileiras em Portugal e imaginários sociais: uma revisão crítica da literatura. CIES e-Working Paper, 106/2011. CIES - IUL, Lisboa, Portugal.

Recuperado em 23, agosto, 2020, de https://repositorio.iscteiul.pt/bitstream/10071/2949/1/CIES-WP106_Gomes.pdf

Hintze, H. C. (2013). Espetáculos e invisibilidades do discurso legitimador do turismo. Tese de Doutorado em Ciências/Ecologia Aplicada. Universidade de São Paulo, Piracicaba, SP, 
Brasil. Recuperado em 23, agosto, 2020, de

https://teses.usp.br/teses/disponiveis/91/91131/tde-04102013-164505/fr.php

Hooks, B. (1995). Intelectuais Negras. Revista Estudos Feministas, 3 (2).

Instituto Brasileiro de Geografia e Estatística - IBGE (2019). Pesquisa Nacional por Amostra de Domicílios Contínua anual. Recuperado em 24, agosto, 2020, de https://sidra.ibge.gov.br/tabela/6786

Instituto de Pesquisa Econômica Aplicada - IPEA (2017). Retrato das Desigualdades de Gênero e Raça - 1995 a 2015. Brasília: IPEA. Recuperado em 24, agosto, 2020, de http://www.ipea.gov.br/retrato/indicadorestrabalhodomesticoremunerado.html

Murguialday, C. (2015). ¿Equidad de género en el turismo? muchas sombras y algunas luces: aproximación a tres experiencias de turismo no convencional. Colección Praxis, 3, Foro de Turismo Responsable. Recuperado em 16, agosto, 2020,

de http://biblioteca.hegoa.ehu.es/downloads/20071/\%2Fsystem\%2Fpdf\%2F3639\%2F_Equid ad_de_genero_en_el_turismo_.pdf

Organização Mundial do Turismo - OMT (2008). Tendências do Turismo Internacional. Madrid: OMT.

Pinheiro, L. B. M. (2015). Negritude, apropriação cultural e a "crise conceitual" das identidades na modernidade. Anais do XXVIII Simpósio Nacional de História. Lugares dos historiadores: velhos e novos desafios. Florianópolis, SC, Brasil. Recuperado em 23, agosto, 2020, de http://www.snh2015.anpuh.org/resources/anais/39/1427821377_ARQUIVO_LISANDRATEXTOCOMPLETOANPUH2015.pdf

Pinho, P. (2018). Turismos Diaspóricos: Mapeando Conceitos e Questões. Tempo Social, 30 (2), 113-131.

Piscitelli, A. (2007a). Corporalidade em confronto: brasileiras na indústria do sexo na Espanha. Revista Brasileira de Ciências Sociais, 22 (64), 17-32.

Piscitelli, A. (2007b). Sexo tropical em um país europeu: migração de brasileiras para a migração de brasileiras para a Itália no marco do "turismo sexual". Estudos Feministas, 15(3): 717-744.

Santos, T. S. (2018). O viajante afro-brasileiro: enegrecendo o turismo. Trabalho de Conclusão de Curso da Graduação em Turismo. Departamento de Relações Públicas, Propaganda e Turismo. Escola de Comunicação e Artes, Universidade de São Paulo. São Paulo, SP, Brasil. Recuperado em 23, agosto, 2020, de http://www3.eca.usp.br/sites/default/files/form/biblioteca/acervo/textos/tc4087-Santos.pdf

Santos, D. U. J., \& Sá, N. S. C. (2020). Salvador, cidade hospitaleira?: uma análise das experiências turísticas de mulheres e crianças. Relatório Final de Iniciação Científica. Projeto Acessibilidade, Mobilidade e Hospitalidade em Destinos Turísticos: respeito, empatia e equidade para viajantes de grupos minoritários. Universidade do Estado da Bahia, Salvador, BA, Brasil. 
Santos, L. R. A., Berteli, A. J. S. C., \& Arantes, R. M. (2016). A estereotipação da mulher negra e os reflexos no turismo brasileiro. Anais do X Fórum Internacional de Turismo do Iguassu. Foz do Iguaçu, PR, Brasil. Recuperado em 16, agosto, 2020, de https://festivaldascataratas.com/wp-content/uploads/2017/04/2.-AESTERIOTIPA\%C3\%87\%C3\%83O-DA-MULHER-NEGRA-E-OS-REFLEXOS-NOTURISMO-BRASILEIRO.pdf

Silva, S. A. (2016). "Sexo e as negas": narrativas estereotipadas e sexista na representação das mulheres negras. Aedos, Porto Alegre, 8(19), 151-166.

Sinhoretto, J., \& Morais, D. S. (2018). Violência e racismo: novas faces de uma afinidade reiterada. Revista de Estudios Sociales, 64, 15-26.

Teles, L. M. S., \& Adi, A. S. (2016). Hipersexualização das Mulheres Negras: aspectos sócio-históricos e a influência da mídia. Ambiente Virtual de Educação Fasbiana. Recuperado em 23, agosto, 2020, de http://avef.fasb.edu.br/pluginfile.php/19321/mod_data/content/125/Hipersexualiza\%C3\%A7 $\% \mathrm{C} 3 \%$ A3o\%20das $\% 20$ Mulheres $\% 20$ Negras $\% 20$ aspectos $\% 20$ s $\%$ C3\%B3ciohist $\%$ C3\%B3ricos\%20e\%20a\%20influ\%C3\%AAncia\%20da\%20m\%C3\%ADdia.pdf

TripAdvisor (2015). Pesquisa com mulheres viajantes. Recuperado em 24, agosto, 2020, de https://tripadvisor.mediaroom.com/2015-03-05-UMA-A-CADA-QUATRO-BRASILEIRASVIAJA-SOZINHA

United Nations World Tourism Organization - UNWTO (2019). Global Report on Women in Tourism: Second Edition. Recuperado em 16, agosto, 2020, de https://www.eunwto.org/doi/book/10.18111/9789284420384

Waiselfisz, J. J. (2012). Mapa da Violência 2012: A Cor dos Homicídios no Brasil. Rio de Janeiro: CEBELA, FLACSO; Brasília: SEPPIR/PR. Recuperado em 23, agosto, 2020, de https://bibliotecadigital.mdh.gov.br/jspui/bitstream/192/83/1/WAISELFISZ_mapaViolencia_c or_2012.pdf

\section{FORMATO PARA CITAÇÃO DESTE ARTIGO}

SANTOS, J. \& COIMBRA DE SÁ, N. S. (2021). A mulher negra viajante: experiências e estratégias de combate à sua (in)visibilidade no turismo. Revista de Turismo Contemporâneo, 9(2), 252-269. https://doi.org/10.21680/2357-8211.2021v9n2ID23584 